\title{
Compromise and Attraction Effects under Prevention and Promotion Motivations
}

\author{
MEHDI MOURALI \\ ULF BÖCKENHOLT \\ MICHEL LAROCHE*
}

\begin{abstract}
This article examines the influence of consumers' motivational orientations on their susceptibilities to context effects. Prevention-focused consumers were found to be more sensitive to the compromise effect and less sensitive to the attraction effect than promotion-focused consumers. In addition, the effects of promotion and prevention motivations were amplified when consumers were asked to justify their choices. Finally, we found that products associated with a prevention concern are more attractive when presented as compromise than asymmetrically dominant options, whereas products associated with a promotion concern are more attractive when presented as asymmetrically dominant options than compromise options.
\end{abstract}

A fascinating literature on context effects has consistently shown that introducing a new alternative to an existing choice set can have a systematic influence on the relative preferences for the original alternatives. One such phenomenon is the attraction or asymmetric dominance effect, first described by Huber, Payne, and Puto (1982). The attraction effect is observed when adding an alternative that is inferior to another alternative in the choice set increases the share of the relatively superior alternative. Another equally intriguing phenomenon is the compromise effect (Simonson 1989), which is observed when adding an extreme option to the choice set shifts the choice preferences in favor of the compromise option.

Such context effects have many practical implications in areas such as new product introduction, product deletion, positioning strategy, and product assortments (Kivetz, Netzer, and Srinivasan 2004; Simonson and Tversky 1992). In addition, they have important theoretical implications, for

*Mehdi Mourali is assistant professor of marketing, Whittemore School of Business and Economics, University of New Hampshire, McConnell Hall, Durham, NH 03824 (mehdi.mourali@unh.edu). Ulf Böckenholt is the Bell Professor of Marketing, Faculty of Management, McGill University, 1001 Sherbrooke St. West, Montreal, QC, Canada, H3A 1G5 (ulf .bockenholt@mcgill.ca). Michel Laroche is the Royal Bank Professor of Marketing, John Molson School of Business, Concordia University, 1455 de Maisonneuve Blvd. West, Montreal, QC, Canada, H3G 1M8 (laroche @jmsb.concordia.ca). Correspondence: Mehdi Mourali. This research was supported partially by the Social Sciences and Humanities Research Council of Canada. The authors thank the editor, associate editor, and the three reviewers for their constructive feedback.

John Deighton served as editor and Stephen Nowlis served as associate editor for this article.

Electronically published June 7, 2007 they violate some fundamental properties underlying most rational choice models. One such assumption is the regularity principle, which asserts that the addition of a new option to the choice set should not increase the probability of choosing any of the original options (Luce 1977). Clearly, both the attraction and compromise effects reflect an increase in the share of the target option after adding a third option. Both context effects are also inconsistent with the principle of independence of irrelevant alternatives (Luce 1959), which implies that a new option added to a given set should take shares from existing options in proportion to their original shares.

A great deal of research has focused on investigating the cognitive processes underlying these effects (Ariely and Wallsten 1995; Dhar and Glazer 1996; Pettibone and Wedell 2000; Simonson and Tversky 1992). Researchers have also examined the influence on the size of context effects of a wide range of potential moderators. These included variables related to the decision task, such as clarity and meaningfulness of the stimulus material, position and similarity of choice alternatives, and task involvement (Mishra, Umesh, and Stem 1993; Ratneshwar, Shocker, and Stewart 1987), variables linked to the individual decision maker, such as need for uniqueness and product knowledge (Sen 1998; Simonson and Nowlis 2000), and variables associated with the social context, such as accountability and culture (Briley, Morris, and Simonson 2000; Simonson 1989). The present investigation adds to the current understanding of context effects by examining the motivational influences behind these decision phenomena. In particular, we examine how consumers' goals and the self-regulatory orientations triggered by these goals might influence their sensitivities to context effects in choice. 


\section{REGULATORY FOCUS AND SENSITIVITY TO CONTEXT EFFECTS}

Consumer goals are conceptualized in terms of Higgins's (1997) regulatory focus theory, which classifies them into two broad categories: ideals and oughts. Ideals denote people's aspirations, hopes, and wishes, whereas oughts stand for people's responsibilities, obligations, and duties. Higgins's (1997) theory posits that ideals and oughts entail distinct self-regulatory systems. In particular, regulation in relation to ideals involves a promotion focus, which is a regulatory state concerned with advancement and accomplishment. In contrast, regulation in relation to oughts involves a prevention focus, which is a regulatory state concerned with protection and safety (Higgins 1997, 1998).

Promotion self-regulation is generally focused on achieving gains and capturing opportunities. This sensitivity to positive outcomes, according to Crowe and Higgins (1997), leads to a preference for eager strategies in goal pursuit. Such strategies involve a concern with achieving "hits" and ensuring against "misses." In contrast, prevention self-regulation is mainly focused on preventing mistakes and avoiding losses. Here, the sensitivity to negative outcomes leads to a preference for vigilant strategies in goal pursuit. A vigilant strategy involves a concern with achieving "correct rejections" and ensuring against "false hits."

A key assumption underlying regulatory focus theory is that, although some people are chronically more promotion oriented and others are chronically more prevention oriented, both systems of self-regulation are presumed to exist in each person and each can be activated separately depending on situational demands (Higgins 1997). With the increasing recognition, in recent years, of the importance of goals and motives in shaping consumer behavior (Ratneshwar, Mick, and Huffman 2000), consumer researchers have found in regulatory focus theory a powerful and parsimonious framework for investigating various phenomena such as persuasion and choice decisions (Aaker and Lee 2001; Chernev 2004a; Pham and Avnet 2004; Zhou and Pham 2004). In the context of choice, for instance, Chernev (2004b) found that product attributes that are compatible with a consumer's regulatory focus tend to be overweighed in a choice decision, while Zhou and Pham (2004) demonstrated that decisions about different financial products tend to trigger the regulatory orientations typically associated with these products, which, in turn, leads to asymmetric sensitivities to potential gains and potential losses.

The central premise of this research is that promotionfocused and prevention-focused consumers differ in their sensitivities to context effects. Consistent with recent theoretical propositions advanced but not tested by Pham and Higgins (2005), we expect that prevention-focused consumers would display a greater susceptibility to the compromise effect, whereas promotion-focused consumers would be more susceptible to the attraction effect.

Prevention-focused consumers who favor vigilant strategies of making correct rejections and avoiding mistakes are expected to avoid extreme options (options that are very attractive on some attribute dimensions but very unattractive on other attribute dimensions). This is because the choice of an extreme option increases the risk of potentially making a poor choice (i.e., by betting on the wrong attribute). Instead, these vigilant consumers should favor the "safer" compromise options, which offer intermediate levels of all attributes and thus minimize the risk of making a mistake.

Furthermore, the presence of asymmetric dominance in a choice set often offers a compelling heuristic for choosing the dominant option (Pettibone and Wedell 2000; Simonson 1989). Because promotion-focused consumers use an eager strategy for achieving hits and ensuring advancement, they should be more sensitive to the dominance heuristic. That is, they should be more likely to view the presence of a dominant brand as an opportunity to be captured and not to be missed. This is consistent with previous research suggesting more heuristic modes of evaluation under promotion versus more systematic modes of evaluation under prevention (Pham and Higgins 2005) and indicating a preference for speed versus accuracy in task completion under promotion focus (Forster, Higgins, and Bianco 2003).

H1: The size of the compromise effect will be greater for prevention-focused consumers than for promotion-focused consumers.

H2: The size of the attraction effect will be greater for promotion-focused consumers than for prevention-focused consumers.

\section{THE EFFECT OF JUSTIFICATION}

Both dominant and compromise options offer convincing reasons for their choice. As a result, one might expect that asking people to elaborate on the reasons for their choices would increase their preferences for compromise and dominant options (Simonson 1989). However, we propose that consumers' motivational orientation plays a critical role in shaping the relationship between justification and susceptibility to context effects.

First, asking people to provide reasons for their choice is akin to asking them to reflect on their goals. Such an exercise may render their regulatory goals even more salient and prompt an active engagement in self-regulation (Zhou and Pham 2004). Because the effects of promotion and prevention focus should be greater when self-regulation is actively engaged, it is expected that promotion-focused respondents will have a lower (higher) preference for compromise (dominant) options when asked to provide reasons for their choice than when not asked to do so. In contrast, prevention-focused participants should be more (less) likely to choose compromise (dominant) options when asked to provide reasons for their choice than when they are not.

A second argument is that, under promotion focus, gainrelated reasons may become both more accessible (more easily retrieved) and more diagnostic (are attributed greater 
weight) than loss-related reasons, whereas the opposite holds under prevention focus. Because asking people to provide reasons for their choice shifts their focus from choosing among alternatives to choosing among reasons (Simonson and Nowlis 2000), asking promotion-focused people to justify their choice will increase their preference for options associated with gain-related reasons (i.e., extreme options and dominant options), whereas asking prevention-focused people to justify their choice will increase their preference for options associated with loss-related reasons (i.e., compromise options).

H3: Justification will increase preference for compromise options under prevention focus but decrease it under promotion focus.

H4: Justification will increase preference for dominant options under promotion focus but decrease it under prevention focus.

\section{THE EFFECT OF PRODUCT TYPE}

We have, so far, speculated on how regulatory focus may influence consumers' choice decisions. There is, however, evidence that promotion and prevention foci may themselves be triggered by the decision context. For instance, Zhou and Pham (2004) suggest that decisions about different products trigger different regulatory concerns. If this is the case, then choices among different products should lead to different patterns of sensitivity to context effects. In particular, decisions among products that consumers associate with a prevention concern are likely to result in higher preferences for compromise options and lower preferences for asymmetrically dominant options than choices among products that consumers associate with a promotion concern. This also implies that, depending on the product type, achieving a compromise position could be either a more or a less effective strategy than achieving asymmetric dominance.

H5: Products associated with a promotion focus will be more attractive when presented as asymmetrically dominant options than when presented as compromise options, whereas products associated with a prevention focus will be more attractive when presented as compromise options than when presented as asymmetrically dominant options.

\section{STUDY 1}

Two hundred forty-eight undergraduate business students at Concordia University (Montreal) participated in study 1 . The sample comprised 130 men (52.4\%) and 118 women (47.6\%). Participants' ages ranged 18-36, with a mean of 22.5 and a standard deviation of 3.3. The goal of study 1 was to test the hypotheses that (1) the compromise effect is greater under prevention focus than under promotion focus and (2) the attraction effect is greater under promotion focus than under prevention focus.

Two factors were manipulated in a $2 \times 2$ (either promotion focus or prevention focus vs. either two or three options in the choice set) between-subjects design. Promotion and prevention foci were manipulated by combining two methods that have been described in the literature. First, participants in the promotion condition were asked to reflect on and write down their most important hopes and aspirations and those in the prevention condition were asked to reflect on and write down their most important duties and obligations (Chernev 2004b; Higgins et al. 1994). This manipulation was intended to prime respondents' ideals versus oughts. Next, respondents in the promotion condition were instructed to think and write about times in the past when trying to achieve something important to them, they performed as well as they ideally would have liked to. Those in the prevention condition were instructed to think and write about times in the past when being careful enough has saved them from getting into trouble (Higgins et al. 2001). This manipulation was intended to make salient respondents' subjective history of success in either using promotion-related eagerness (promotion pride) or prevention-related vigilance (prevention pride) in goal attainment.

Following the regulatory focus manipulations, respondents were presented with a series of choice tasks. Participants in the two-option (core set) condition were presented with choice sets, in six product categories, comprising brands $\mathrm{A}$ and $\mathrm{B}$ only. Participants in the three-option (extended set) condition chose among brands $\mathrm{A}, \mathrm{B}$, and $\mathrm{C}$ in six product categories. ${ }^{1}$ Respondents indicated their choice and their evaluation of the attractiveness of each option, the latter on a seven-point scale. Respondents' gender and age were also recorded.

\section{Choice Patterns}

In general, compromise and attraction effects are measured by comparing the relative shares of choice options between the core and the extended sets (Chernev 2004a; Simonson and Tversky 1992). In particular, if $P(\mathrm{~B} ; \mathrm{A}, \mathrm{C})$ reflects the share of brand $B$ in the extended set $\{A, B, C\}$ and $P(\mathrm{~A} ; \mathrm{B}, \mathrm{C})$ reflects the share of brand $\mathrm{A}$ in the extended set $\{\mathrm{A}, \mathrm{B}, \mathrm{C}\}$, then $P_{\mathrm{C}}(\mathrm{B} ; \mathrm{A})$ is the share of brand $\mathrm{B}$ relative to brand $\mathrm{A}$ in the same extended set $\{\mathrm{A}, \mathrm{B}, \mathrm{C}\}$, with

$$
P_{\mathrm{C}}(\mathrm{B} ; \mathrm{A})=\frac{P(\mathrm{~B} ; \mathrm{A}, \mathrm{C})}{P(\mathrm{~B} ; \mathrm{A}, \mathrm{C})+P(\mathrm{~A} ; \mathrm{B}, \mathrm{C})} .
$$

Compromise and attraction effects are typically measured by $\Delta P_{\mathrm{B}}=P_{\mathrm{C}}(\mathrm{B} ; \mathrm{A})-P(\mathrm{~B} ; \mathrm{A})$, where $\Delta P_{\mathrm{B}}$ refers to the change in the share of brand $\mathrm{B}$ relative to brand $\mathrm{A}$ as a result of adding brand $\mathrm{C}$ to the core set $\{\mathrm{A}, \mathrm{B}\}$, and $P(\mathrm{~B}$; $\mathrm{A})$ is the share of brand $\mathrm{B}$ relative to brand $\mathrm{A}$ in the core

\footnotetext{
${ }^{1}$ The products used in this study were selected on the basis of a pilot study that assessed product familiarity, decision involvement, and attribute importance (see app. A for a description of the choice sets).
} 
TABLE 1

COMPROMISE EFFECT ACROSS PROMOTION AND PREVENTION FOCI

\begin{tabular}{|c|c|c|c|c|c|c|}
\hline \multirow{2}{*}{$\begin{array}{l}\text { Shares } \\
(\%)\end{array}$} & \multicolumn{3}{|c|}{ Promotion focus } & \multicolumn{3}{|c|}{ Prevention focus } \\
\hline & Toothpaste & Printer & Restaurant & Toothpaste & Printer & Restaurant \\
\hline$p(\mathrm{~A} ; \mathrm{B})$ & 41.9 & 56.4 & 50.0 & 48.4 & 69.4 & 53.2 \\
\hline$p(\mathrm{~B} ; \mathrm{A})$ & 58.1 & 43.6 & 50.0 & 51.6 & 30.6 & 46.8 \\
\hline$p(\mathrm{~A} ; \mathrm{B}, \mathrm{C})$ & 24.2 & 33.9 & 30.7 & 11.3 & 25.8 & 29.0 \\
\hline$p(B ; A, C)$ & 48.4 & 50.0 & 53.2 & 62.9 & 58.1 & 62.9 \\
\hline$p(C ; A, B)$ & 27.4 & 16.1 & 16.1 & 25.8 & 16.1 & 8.1 \\
\hline$p_{\mathrm{C}}(\mathrm{B} ; \mathrm{A})$ & 66.7 & 59.6 & 63.5 & 84.8 & 69.2 & 68.4 \\
\hline$\Delta p_{\mathrm{B}}$ & 8.6 & 16.0 & 13.5 & 33.2 & 38.6 & 21.6 \\
\hline$\chi^{2}(1)$ & .816 & 2.92 & 2.08 & 5.68 & 16.9 & 5.68 \\
\hline$p$-value & .366 & .087 & .149 & .017 & $<.001$ & .017 \\
\hline
\end{tabular}

set $\{\mathrm{A}, \mathrm{B}\}$. Tables 1 and 2 summarize the choice shares of each alternative across all experimental conditions and for all products. The tables also report the sizes of the compromise and attraction effects (i.e., $\Delta p_{\mathrm{B}}$ ) and whether these effects are statistically significant (i.e., $H 0=p_{\mathrm{C}}(\mathrm{B} ; \mathrm{A})=$ $p(\mathrm{~B} ; \mathrm{A}))$.

The results indicate a marked difference in the size of the compromise effect across the promotion and prevention conditions. In the case of toothpaste, for instance, the relative share of the middle option increased by $33.2 \%(p=.017)$ under prevention focus but only by $8.6 \%(p=.366)$ under promotion focus. Similarly, the share of option B, in the case of printer, increased by $38.6 \%(p<.001)$ under prevention focus, while it increased by $16 \%(p=.087)$ under promotion focus. Finally, in the case of restaurant, the share of option B increased by $21.6 \%(p=.017)$ under prevention focus versus $13.5 \%(p=.149)$ under promotion focus. In fact, the compromise effect was statistically significant for all three products under prevention focus, whereas it failed to reach statistical significance for any of the three products under promotion focus.

Furthermore, the results suggest a notable difference in the size of the attraction effect across the promotion and prevention conditions. The share of the dominant phone, for instance, increased by $11.3 \%(p=.128)$ under promotion focus, but it decreased by $4.8 \%(p=.524)$ under prevention focus. In the case of helmets, the share of the dominant option increased by $11.7 \%(p=.336)$ under promotion focus, while it increased by a mere $0.4 \%(p=.971)$ under prevention focus. Although changes in the share of the dominant option did not reach statistical significance, suggesting weak attraction effects in the case of both helmet and phone, there seems to be an important difference between the sizes of these effects across promotion and prevention foci $(11.7 \%$ vs. $0.4 \%$ for helmet, and $11.3 \%$ vs. $-4.8 \%$ for phone). Finally, the share of the dominant grill increased by a significant $27.4 \%$ ( $p=.002$ ) under promotion focus, while it only gained a marginal $8.8 \%(p=.320)$ under prevention focus.

Thus, at first glance, these results seem in line with the predicted effects of regulatory focus on consumer sensitivity to compromise and attraction effects. A complete test of hypotheses 1 and 2, however, requires a statistical test of the difference between $\Delta p_{\mathrm{B}}$ (promotion) and $\Delta p_{\mathrm{B}}$ (prevention), which is presented in the next section.

\section{Hypothesis Testing}

By design, the data collected in study 1 are hierarchically structured. The choice scenarios (product category, choice, attractiveness ratings) are nested within individuals since each individual was faced with six choice scenarios. In addition, individual differences can be related to the promotion- versus prevention-focus condition, the choice set (core vs. extended), age, and gender.

Multilevel Analysis of the Compromise Effect. The level-2 (or between-subject) part of the data consists of 248 respondents, who each chose from three scenarios related to the compromise effect, yielding 744 level-1 observations. Since the compromise effect is measured by the change in the share of option $B$ relative to option $A$, any choice of option $\mathrm{C}$ was deleted from the level-1 (or within-subject) data set. This reduced the size of the final level-1 sample to 676 observations. This approach is in line with previous calculations of context effects and is more conservative because it reduces the power of testing the effects of interest.

At level 1, the log odds of choosing option B was specified

TABLE 2

\section{ATTRACTION EFFECT ACROSS PROMOTION AND PREVENTION FOCI}

\begin{tabular}{|c|c|c|c|c|c|c|}
\hline \multirow{2}{*}{$\begin{array}{l}\text { Shares } \\
(\%)\end{array}$} & \multicolumn{3}{|c|}{ Promotion focus } & \multicolumn{3}{|c|}{ Prevention focus } \\
\hline & Helmet & Phone & Grill & Helmet & Phone & Grill \\
\hline$p(\mathrm{~A} ; \mathrm{B})$ & 50.0 & 83.9 & 72.6 & 45.2 & 74.2 & 64.5 \\
\hline$p(\mathrm{~B} ; \mathrm{A})$ & 50.0 & 16.1 & 27.4 & 54.8 & 25.8 & 35.5 \\
\hline$p(\mathrm{~A} ; \mathrm{B}, \mathrm{C})$ & 37.1 & 72.6 & 45.2 & 41.9 & 79.0 & 54.8 \\
\hline$p(\mathrm{~B} ; \mathrm{A}, \mathrm{C})$ & 59.7 & 27.4 & 54.8 & 51.6 & 21.0 & 43.6 \\
\hline$p(\mathrm{C} ; \mathrm{A}, \mathrm{B})$ & 3.2 & 0 & 0 & 6.5 & 0 & 1.6 \\
\hline$p_{\mathrm{C}}(\mathrm{B} ; \mathrm{A})$ & 61.7 & 27.4 & 54.8 & 55.2 & 21.0 & 44.3 \\
\hline$\Delta p_{\mathrm{B}}$ & 11.7 & 11.3 & 27.4 & .4 & -4.8 & 8.8 \\
\hline$\chi^{2}(1)$ & 1.68 & 2.32 & 9.63 & .001 & .405 & .989 \\
\hline$p$-value & .336 & .128 & .002 & .971 & .524 & .320 \\
\hline
\end{tabular}


as varying across products. In addition, the log odds of choosing $\mathrm{B}$ for each product was modeled at level 2 to be a function of individuals' regulatory focus condition (represented by the variable "regcond"), whether they chose from a core or an extended set (represented by the variable "options"), and the interaction of these variables (represented by the variable "regcond x options"). As a result, the two-level model can be written as:

$$
\begin{aligned}
\log [ & \left.P\left(\mathrm{~B}_{\mathrm{ij}}\right) /\left(1-P\left(\mathrm{~B}_{\mathrm{ij}}\right)\right)\right]=\gamma_{00}+\gamma_{10}(\text { printer })_{\mathrm{ij}} \\
& +\gamma_{20}(\text { restaurant })_{\mathrm{ij}}+\gamma_{01}(\text { regcond })_{\mathrm{j}}+\gamma_{02}(\text { options })_{\mathrm{j}} \\
& +\gamma_{03}(\text { regcond } \times \text { options })_{\mathrm{j}}+\gamma_{11}(\text { regcond })_{\mathrm{j}}(\text { printer })_{\mathrm{ij}} \\
& +\gamma_{12}(\text { options })_{\mathrm{j}}(\text { printer })_{\mathrm{ij}}+\gamma_{13}(\text { regcond } \times \text { options })_{\mathrm{j}}(\text { printer })_{\mathrm{ij}} \\
& +\gamma_{21}(\text { regcond })_{\mathrm{j}}(\text { restaurant })_{\mathrm{ij}}+\gamma_{22}(\text { options })_{\mathrm{j}}(\text { restaurant })_{\mathrm{ij}} \\
& +\gamma_{23}(\text { regcond } \times \text { options })_{\mathrm{j}}(\text { restaurant })_{\mathrm{ij}}+\mathrm{u}_{0 \mathrm{j}},
\end{aligned}
$$

where $\mathrm{u}_{0 \mathrm{j}}$ is specified to follow a normal distribution with variance $\tau_{00}$. The two-level choice model was estimated with the highly accurate Laplace approximation to the maximum likelihood solution (Raudenbush et al. 2001), using the multilevel software HLM5 for Windows (Raudenbush et al. 2000).

The results indicate no main effect of regulatory focus $\left(\gamma_{01}=-.372 ; p=.207\right)$, but a positive main effect of the number of options in the choice set $\left(\gamma_{02}=.610 ; p=\right.$ .034). The latter effect suggests that the probability of choosing option B was generally higher among those choosing from the extended set than among those choosing from the core set. Most important, the interaction effect was significant $\left(\gamma_{03}=1.02 ; p=.020\right)$. This positive interaction is consistent with the prediction of hypothesis 1 , according to which the increase in the probability of choosing option B as a result of adding option $C$ to the core set is higher under prevention focus than under promotion focus. Finally, the effects of regcond, options, and regcond $\times$ options did not vary across product categories. Indeed, the cross-level interactions $\left(\gamma_{11}, \gamma_{12}, \gamma_{13}, \gamma_{21}, \gamma_{22}, \gamma_{23}\right)$ were below the significance level.

The analyses were replicated using the attractiveness ratings. Since the compromise effect reflects the attractiveness of the compromise brand (option $\mathrm{B}$ ) relative to the other brand in the core set (option A), an index of relative attractiveness of option B was created by subtracting the attractiveness score of option A from the attractiveness score of option B. A model similar to equation 1, but using the relative attractiveness index as outcome, was estimated using maximum likelihood methods.

Consistent with the choice model, we found no main effect of regulatory focus $\left(\gamma_{01}=-.172 ; p=.331\right)$, a positive effect of the number of options in the choice set $\left(\gamma_{02}=\right.$ .413; $p=.036)$, and a significant interaction effect $\left(\gamma_{03}=.763 ; p=.004\right)$ on the relative attractiveness of the compromise brand. In addition, the effects of options, regcond, and regcond $\times$ options did not vary across product categories. Taken together, the results from the choice model and the relative attractiveness model provide some evidence that the size of the compromise effect (measured by the difference in the relative share (attractiveness) of option B across the core and the extended set) is larger under prevention than under promotion focus.

Multilevel Analysis of the Attraction Effect. As in the case of the compromise effect, the outcome variables considered here are the choice (i.e., log odds) and the relative attractiveness of option B. The difference, of course, is in the choice scenarios considered (grill, helmet, and phone in this case). Here too, the level-2 data set consists of 248 respondents, who each answered three choice scenarios related to the attraction effect. After deleting observations in which option $\mathrm{C}$ was chosen, the final level-1 sample yielded 737 observations.

The log odds of choosing option B was allowed to vary across products at level 1 , and the probability of choosing B for each product was assumed to be a function of individuals' regulatory focus condition (regcond), whether they chose from a core or an extended set (options), and the interaction of these variables (regcond $x$ options):

$$
\begin{aligned}
\log [ & \text { P } \left.\left(\mathrm{B}_{\mathrm{ij}}\right) /\left(1-P\left(\mathrm{~B}_{\mathrm{ij}}\right)\right)\right]=\gamma_{00}+\gamma_{10}(\text { helmet })_{\mathrm{ij}} \\
& +\gamma_{20}(\text { phone })_{\mathrm{ij}}+\gamma_{01}(\text { regcond }) \mathrm{j}+\gamma_{02}(\text { options })_{\mathrm{j}} \\
& +\gamma_{03}(\text { regcond } \times \text { options })_{\mathrm{j}}+\gamma_{11}(\text { regcond })_{\mathrm{j}}(\text { helmet })_{\mathrm{ij}} \\
& +\gamma_{12}(\text { options })(\text { helmet })_{\mathrm{ij}}+\gamma_{13}(\text { regcond } \times \text { options })_{\mathrm{j}}(\text { helmet })_{\mathrm{ij}} \\
& +\gamma_{21}(\text { regcond })_{\mathrm{j}}(\text { phone })_{\mathrm{ij}}+\gamma_{22}(\text { options })_{\mathrm{j}}(\text { phone })_{\mathrm{ij}} \\
& +\gamma_{23}(\text { regcond } \times \text { options })_{\mathrm{j}}(\text { phone })_{\mathrm{ij}}+\mathrm{u}_{0 \mathrm{j}} .
\end{aligned}
$$

The results show no main effect of regulatory focus $\left(\gamma_{01}=.421 ; p=.118\right)$ and a significant main effect of options $\left(\gamma_{02}=.837 ; p=.002\right)$, indicating that the probability of choosing option B was generally higher among those choosing from the extended set than among those choosing from the core set. Further, in support of hypothesis 2, we found a significant interaction between regulatory focus and the number of options $\left(\gamma_{03}=-.792 ; p=.034\right)$. This interaction effect was invariant across products.

Using the same measure of relative attractiveness of option $\mathrm{B}$ as in the compromise analysis, we found no main effect of regulatory focus $\left(\gamma_{01}=.244 ; p=.107\right)$, a positive main effect of options $\left(\gamma_{02}=.690 ; p<.001\right)$, and a significant interaction effect $\left(\gamma_{03}=-.515 ; p=.028\right)$ on the relative attractiveness of brand $\mathrm{B}$. These findings are parallel to those obtained from the analysis of choices and provide further support to hypothesis 2 . In addition, the interaction effect did not vary across products, as indicated by nonsignificant $\gamma_{13}$ and $\gamma_{23}$ coefficients. 


\section{STUDY 2}

The sample for study 2 consisted of 246 undergraduate business students at Concordia University. The respondents were $54.1 \%$ males and were ages $18-36$, with a mean of 22.7 and a standard deviation of 3.1. Study 2 was designed to test the hypotheses that (1) justification will increase preference for compromise options under prevention focus but decrease it under promotion focus and (2) justification will increase preference for dominant options under promotion focus but decrease it under prevention focus.

Two factors were manipulated in a $2 \times 2$ (either promotion focus or prevention focus vs. either justification or control) between-subjects design. Promotion and prevention foci were manipulated as in study 1 . One hundred twentytwo respondents in the justification condition were asked to provide reasons for choosing one option over the others. Consistent with past research (Briley et al. 2000), respondents were instructed to do so after reviewing each of the choice scenarios but before indicating their choices and rating the options. The control group was composed of the 124 respondents from study 1, who made their decisions from the extended choice sets. Following the regulatory focus manipulations, respondents were presented with four of the six extended choice scenarios used in study 1 (toothpaste and restaurant for the compromise effect; and grill and helmet for the attraction effect). As in study 1, respondents indicated their choice and their evaluation of the attractiveness of each option. Respondents' gender and age were also recorded.

\section{Choice Patterns}

The choice shares across experimental conditions are presented in tables 3 and 4 . The tables also report the differences in the share of option $\mathrm{B}$, that is, $\Delta p(\mathrm{~B} ; \mathrm{A}, \mathrm{C})$, between the justification and the control conditions and whether these differences are statistically significant.

Justification had opposite effects on consumers' preference for compromise options across the prevention and pro-

\section{TABLE 3}

\begin{tabular}{|c|c|c|c|c|}
\hline & \multicolumn{2}{|c|}{ Promotion } & \multicolumn{2}{|c|}{ Prevention } \\
\hline & Toothpaste & Restaurant & Toothpaste & Restauran \\
\hline \multicolumn{5}{|l|}{ Control: } \\
\hline$p(\mathrm{~A} ; \mathrm{B}, \mathrm{C})$ & 24.2 & 30.7 & 11.3 & 29.0 \\
\hline$p(\mathrm{~B} ; \mathrm{A}, \mathrm{C})$ & 48.4 & 53.2 & 62.9 & 62.9 \\
\hline$p(C ; A, B)$ & 27.4 & 16.1 & 25.8 & 8.1 \\
\hline \multicolumn{5}{|l|}{ Justification: } \\
\hline$p(\mathrm{~A} ; \mathrm{B}, \mathrm{C})$ & 34.4 & 44.2 & 8.2 & 11.5 \\
\hline$p(\mathrm{~B} ; \mathrm{A}, \mathrm{C})$ & 34.4 & 41.0 & 78.7 & 82.0 \\
\hline$p(\mathrm{C} ; \mathrm{A}, \mathrm{B})$ & 31.2 & 14.8 & 13.1 & 6.5 \\
\hline$\Delta p(B ; A, C)$ & -14.0 & -12.2 & 15.8 & 19.1 \\
\hline$x^{2}(1)$ & 2.47 & 1.85 & 3.70 & 5.59 \\
\hline$p$-value & .116 & .174 & .054 & .018 \\
\hline
\end{tabular}

TABLE 4

EFFECT OF JUSTIFICATION ON CHOICE OF DOMINANCE ACROSS PROMOTION AND PREVENTION FOCI

\begin{tabular}{cccccc}
\hline \hline & \multicolumn{2}{c}{ Promotion } & & \multicolumn{2}{c}{ Prevention } \\
\cline { 2 - 3 } \cline { 6 - 6 } & Grill & Helmet & & Grill & Helmet \\
\hline & & & & \\
Control: & & & & \\
$p(\mathrm{~A} ; \mathrm{B}, \mathrm{C})$ & 45.2 & 37.1 & & 54.8 & 41.9 \\
$p(\mathrm{~B} ; \mathrm{A}, \mathrm{C})$ & 54.8 & 59.7 & & 43.6 & 51.6 \\
$p(\mathrm{C} ; \mathrm{A}, \mathrm{B})$ & 0 & 3.2 & & 1.6 & 6.5 \\
Justification: & & & & \\
$p(\mathrm{~A} ; \mathrm{B}, \mathrm{C})$ & 24.6 & 19.7 & & 59.0 & 49.2 \\
$p(\mathrm{~B} ; \mathrm{A}, \mathrm{C})$ & 72.1 & 75.4 & & 36.1 & 39.3 \\
$p(\mathrm{C} ; \mathrm{A}, \mathrm{B})$ & 3.3 & 4.9 & & 4.9 & 11.5 \\
$\Delta p(\mathrm{~B} ; \mathrm{A}, \mathrm{C})$ & 17.3 & 15.7 & & -7.5 & -12.3 \\
$\chi^{2}(1)$ & 3.96 & 3.47 & & .718 & 1.87 \\
$p$-value & .047 & .063 & & .397 & .172 \\
\hline
\end{tabular}

motion conditions. Consistent with hypothesis 3, the share of the compromise toothpaste increased by $15.8 \%$ under prevention focus, but it was reduced by $14.0 \%$ under promotion focus. Similarly, the share of the compromise restaurant, when respondents were asked to justify their choice, increased by $19.1 \%$ under prevention focus and decreased by $12.2 \%$ under promotion focus.

The effect of justification on consumers' preference for dominant options was also noticeably different across promotion and prevention foci. In line with hypothesis 4 , the share of the dominant grill increased by $17.3 \%$ under promotion focus, but it decreased by $7.5 \%$ under prevention focus. In the case of helmets, the share of the dominant option increased by $15.7 \%$ under promotion focus, while it decreased by $12.3 \%$ under prevention focus. These results seem to support the predictions made in hypotheses 3 and 4. A complete test of the hypotheses on the difference between $\Delta p(\mathrm{~B} ; \mathrm{A}, \mathrm{C})$ (promotion) and $\Delta p(\mathrm{~B} ; \mathrm{A}, \mathrm{C})$ (prevention) is presented in the next section.

\section{Hypothesis Testing}

Multilevel Analysis of the Preference for Compromise Options. Here again, we have data on choice scenarios, which are nested within individuals. The level-2 data set consists of 246 respondents, who each answered two choice scenarios related to their preference for compromise options. This produced 492 level-1 observations.

Choices of brand B were analyzed by a two-level model. Specifically, the log odds of choosing B for each product was modeled, at level 2, to be a function of individuals' regulatory focus condition, whether they had to justify their choice (represented by the variable "reasons"), and the interaction of these variables (represented by the variable "reg- 
cond $\times$ reasons"). As a result, the two-level model was expressed as:

$$
\begin{aligned}
\log \left[\mathrm{P}\left(\mathrm{B}_{\mathrm{ij}}\right) /\left(1-P\left(\mathrm{~B}_{\mathrm{ij}}\right)\right)\right]=\gamma_{00}+\gamma_{10}(\text { restaurant })_{\mathrm{ij}} \\
\quad+\gamma_{01}(\text { regcond })_{\mathrm{j}}+\gamma_{02}(\text { reasons })_{\mathrm{j}}+\gamma_{03}(\text { regcond } \times \text { reasons })_{\mathrm{j}} \\
\quad+\gamma_{11}(\text { regcond })_{\mathrm{j}}(\text { restaurant })_{\mathrm{ij}}+\gamma_{12}(\text { reasons })_{\mathrm{j}}(\text { restaurant })_{\mathrm{ij}} \\
\quad+\gamma_{13}(\text { regcond } \times \text { reasons })_{\mathrm{j}}(\text { restaurant })_{\mathrm{ij}}+\mathrm{u}_{0 \mathrm{j}} .
\end{aligned}
$$

Regulatory focus had no main effect $\left(\gamma_{01}=.531 ; p=\right.$ .067) on respondents' log odds of choosing a compromise brand, whereas justification had a negative main effect $\left(\gamma_{02}=-.577 ; p=.036\right)$. Most importantly, there was a significant interaction effect $\left(\gamma_{03}=1.51 ; p=.001\right)$. Thus, as expected, the increase in the probability of choosing the compromise brand as a result of justification is higher under prevention focus than under promotion focus (since it is supposed to decrease under promotion focus). Moreover, the effects of regcond, options, and regcond $\times$ options did not vary across product categories.

The analysis was replicated using an index of relative attractiveness of option B as the outcome variable. This index was created by subtracting the average attractiveness score given to the two extreme options from the attractiveness score of option $\mathrm{B}$. We found a significant interaction effect of regulatory focus and reasons $\left(\gamma_{03}=.822 ; p<\right.$ .001 ) on consumer preference for compromise options and, thus, additional support to hypothesis 3 . In addition, justification $\left(\gamma_{02}=-.413 ; p=.018\right)$ had a negative main effect on the relative attractiveness of the compromise brand, while regulatory focus had a positive main effect $\left(\gamma_{01}=.375\right.$; $p=.022$ ). Finally, the effects of regulatory focus, justification, and their interaction did not vary between products.

Multilevel Analysis of the Preference for Dominant Options. As in the previous analysis, the level-1 data set consisted of 492 observations ( 246 respondents $\times 2$ choice scenarios). The choice model was expressed as follows:

$$
\begin{aligned}
\log [ & \left.P\left(\mathrm{~B}_{\mathrm{ij}}\right) /\left(1-P\left(\mathrm{~B}_{\mathrm{ij}}\right)\right)\right]=\gamma_{00}+\gamma_{10}(\text { helmet })_{\mathrm{ij}} \\
& +\gamma_{01}(\text { regcond })_{\mathrm{j}}+\gamma_{02}(\text { reasons })_{\mathrm{j}}+\gamma_{03}(\text { regcond } \times \text { reasons })_{\mathrm{j}} \\
& +\gamma_{11}(\text { regcond })_{\mathrm{j}}(\text { helmet })_{\mathrm{ij}}+\gamma_{12}(\text { reasons })_{\mathrm{j}}(\text { helmet })_{\mathrm{ij}} \\
& +\gamma_{13}(\text { regcond } \times \text { reasons })_{\mathrm{j}}(\text { helmet })_{\mathrm{ij}}+\mathrm{u}_{0 \mathrm{j}} .
\end{aligned}
$$

We found no main effect of regulatory focus $\left(\gamma_{01}=-.413\right.$; $p=.128$ ) on the choice of the dominant brand. The analysis, however, revealed a positive main effect of reasons $\left(\gamma_{02}=.782 ; p=.008\right)$, suggesting that the probability of choosing the dominant brand was generally higher among those who had to justify their choice than among those who did not. Most importantly, the interaction between regulatory focus and justification was significant $\left(\gamma_{03}=-1.21\right.$; $p=.004)$. The negative sign of the interaction term is consistent with hypothesis 4 , which predicts that an increase in the probability of choosing the dominant brand as a result of justification would be higher among promotion-focused individuals than among prevention-focused individuals (since it is supposed to decrease under prevention focus). Furthermore, the effects of regulatory focus, justification, and their interaction did not vary between products.

The analysis was replicated using relative attractiveness as outcome and confirmed the interaction effect of regulatory focus and reasons $\left(\gamma_{03}=-.711 ; p=.004\right)$ on consumer preference for dominant brands and, thus, offered additional support to hypothesis 4 . The analysis also revealed a positive main effect of justification $\left(\gamma_{02}=.464\right.$; $p=.015)$ and a negative main effect of regulatory focus $\left(\gamma_{01}=-.351 ; p=.041\right)$ on the relative attractiveness of brand B. Finally, the effects of regulatory focus, justification, and their interaction did not vary between products.

\section{STUDY 3}

The sample for study 3 comprised 232 undergraduate business students at Bishops University. The respondents were $52.2 \%$ males ages $18-31$, with a mean of 22.7 and a standard deviation of 1.94. Study 3 was designed to test hypothesis 5 , which predicts that products associated with a promotion focus would be more attractive when presented as asymmetrically dominant options than when presented as compromise options, whereas products associated with a prevention focus would be more attractive when presented as compromise options than when presented as asymmetrically dominant options.

Two factors were manipulated in a $2 \times 2$ (either promotion-priming products or prevention-priming products vs. either choice scenarios with compromise structures or choice scenarios with asymmetric dominance structures) mixed design. The product type was manipulated within subjects. Each participant was faced with four choice scenarios; two involving promotion-priming products (wine and restaurant) and two involving prevention priming products (sunscreen and mouthwash). These products were selected because consumers' concerns when purchasing and using them were thought to differ in their regulatory orientation. The descriptive attributes for these products were similar to those used in previous studies of context effects (Chernev 2004a). Half of the respondents were randomly assigned to the compromise condition, and the other half to the asymmetric dominance condition. The values of the varying attributes for options A and B in each choice scenario were identical across the compromise and dominance conditions. Attribute values for option $\mathrm{C}$ were arranged to render option $\mathrm{B}$ either a compromise option or an asymmetrically dominant option that dominates $\mathrm{C}$ but not $\mathrm{A}$ (see apps. B and $\mathrm{C}$ ). As in studies 1 and 2, we measured respondents' choices and their evaluation of the attractiveness of each option in addition to recording their gender and age. 
TABLE 5 CHOICE OF COMPROMISE VERSUS DOMINANT BRANDS
ACROSS PRODUCT TYPES

\begin{tabular}{lcccc}
\hline \hline & $p(\mathrm{~A} ; \mathrm{B}, \mathrm{C})$ & $p(\mathrm{~B} ; \mathrm{A}, \mathrm{C})$ & $p(\mathrm{C} ; \mathrm{A}, \mathrm{B})$ & $p_{\mathrm{C}}(\mathrm{B} ; \mathrm{A})$ \\
\hline Compromise & 7.8 & 89.7 & 2.6 & 92.0 \\
Dominant & 29.9 & 67.5 & 2.6 & 69.3 \\
Pearson $\chi^{2}(1)$ & 18.4 & 16.7 & 0 & 18.5 \\
& $(<.001)$ & $(<.001)$ & $(.983)$ & $(<.001)$ \\
Compromise & 30.4 & 59.1 & 10.4 & 66.0 \\
Dominant & 55.6 & 41.9 & 2.6 & 43.0 \\
Pearson $\chi^{2}(1)$ & 14.9 & 6.9 & 5.9 & 11.6 \\
& $(<.001)$ & $(.009)$ & $(.015)$ & $(.001)$ \\
Compromise & 32.2 & 33.0 & 34.8 & 50.7 \\
Dominant & 23.1 & 73.5 & 3.4 & 76.1 \\
Pearson $\chi^{2}(1)$ & 2.4 & 38.2 & 37.1 & 13.0 \\
& $(.121)$ & $(<.001)$ & $(<.001)$ & $(<.001)$ \\
Compromise & 67.0 & 27.8 & 5.2 & 29.4 \\
Dominant & 55.6 & 43.6 & .9 & 44.0 \\
Pearson $\chi^{2}(1)$ & 3.2 & 6.3 & 3.8 & 5.2 \\
& $(.075)$ & $(.012)$ & $(.052)$ & $(.023)$ \\
\hline
\end{tabular}

NoTE.-Numbers in parentheses are $p$-values.

In manipulating product type, we selected sunscreen and mouthwash as prevention-type products, and wine and restaurant as promotion-type products. The reasoning was that people's main concerns when buying or using products such as sunscreen and mouthwash would be to avoid or minimize some negative outcomes (e.g., sunburn and bad breath). In contrast, the main concerns when purchasing products such as a bottle of wine or a dinner at a fine restaurant would be to achieve or maximize some positive outcomes (e.g., pleasure). To test this, we asked the respondents at the end of the questionnaire to distribute 100 points between two general goals (achieving a positive outcome versus avoiding a negative outcome) that they might have when purchasing each of the four products.

As expected, the mean scores of promotion concern for wine $\left(M_{\text {wine }}=87.2, \mathrm{SD}_{\text {wine }}=14.9\right)$ and restaurant $\left(M_{\text {rest }}=\right.$ 87.0, $\left.\mathrm{SD}_{\text {rest }}=13.7\right)$ were significantly higher $(F=562.3$; $p<.001)$ than those for sunscreen $\left(M_{\text {suns }}=23.9, \mathrm{SD}_{\text {suns }}=\right.$ 26.6) and mouthwash $\left(M_{\text {mwash }}=38.9, \mathrm{SD}_{\text {mwash }}=25.5\right)$.

\section{Choice Patterns}

The choice shares of each alternative across all experimental conditions and for all products are presented in table 5 . The table also reports the share of brand $\mathrm{B}$ relative to brand $\mathrm{A}\left(p_{\mathrm{C}}(\mathrm{B} ; \mathrm{A})\right)$.

In the case of prevention-type products, the share of brand $\mathrm{B}$ relative to brand $\mathrm{A}$ was much higher when $\mathrm{B}$ was presented as a compromise brand than as an asymmetrically dominant brand $\left(p_{\mathrm{C}}(\mathrm{B} ; \mathrm{A})_{\text {compr }}=92.0 \%\right.$ vs. $p_{\mathrm{C}}(\mathrm{B} ; \mathrm{A})_{\mathrm{dom}}=69.3 \% ; \chi^{2}(1)=18.5 ; p=.001$ for sunscreen, and $p_{\mathrm{C}}(\mathrm{B} ; \mathrm{A})_{\mathrm{compr}}=66.0 \%$ vs. $p_{\mathrm{C}}(\mathrm{B} ; \mathrm{A})_{\mathrm{dom}}=$ $43.0 \% ; \chi^{2}(1)=11.6 ; p=.001$ for mouthwash). These proportions were reversed for promotion-type products. In this case, the relative share of brand B was higher when B was presented as an asymmetrically dominant brand than as a compromise brand $\left(p_{\mathrm{C}}(\mathrm{B} ; \mathrm{A})_{\text {compr }}=50.7 \%\right.$ vs. $p_{\mathrm{C}}(\mathrm{B} ; \mathrm{A})_{\mathrm{dom}}=76.1 \% ; \chi^{2}(1)=13.0 ; p<.001$ for wine, and $p_{\mathrm{C}}(\mathrm{B} ; \mathrm{A})_{\mathrm{compr}}=29.4 \%$ vs. $p_{\mathrm{C}}(\mathrm{B} ; \mathrm{A})_{\mathrm{dom}}=44.0 \%$; $\chi^{2}(1)=5.2 ; p=.023$ for restaurant).

The results are thus consistent with the predictions of hypothesis 5 . However, to formally test whether the effect of context on choice is dependent on the product type, both context and product type variables must be analyzed simultaneously.

\section{Hypothesis Testing}

A product type variable "ptype" was created and was coded 0 for prevention-priming products (i.e., sunscreen and mouthwash) and 1 for promotion-priming products (i.e., wine and restaurant). A context variable "context" was coded 0 when option B was a compromise brand and 1 when option B was a dominant brand. Two hundred thirtytwo participants chose and rated alternatives in four different product categories. This produced 928 level-1 observations. After deleting choices of brand $\mathrm{C}$, the final level-1 data set was reduced to 856 observations.

At level 1, the choice of option B was specified as varying across product types. In addition, the probability of choosing B for each product type was modeled, at level 2, to be a function of the choice set structure (compromise vs. dominance). As a result, the two-level model can be written as:

$$
\begin{aligned}
& \log \left[P\left(\mathrm{~B}_{\mathrm{ij}}\right) /\left(1-P\left(\mathrm{~B}_{\mathrm{ij}}\right)\right)\right]=\gamma_{00}+\gamma_{10}(\text { ptype })_{\mathrm{ij}} \\
& \quad+\gamma_{01}(\text { context })_{\mathrm{j}}+\gamma_{11}(\text { context })_{\mathrm{j}}(\text { ptype })_{\mathrm{ij}}+\mathrm{u}_{0 \mathrm{j}} .
\end{aligned}
$$

The results indicate that context had no main effect on respondents' probability of choosing brand $\mathrm{B}\left(\gamma_{01}=-.199\right.$; $p=.537)$. Most importantly, a significant cross-level interaction $\left(\gamma_{11}=1.15 ; p=.014\right)$ indicates that the effect of context on choice was moderated by the product type. The positive sign of the interaction is consistent with hypothesis 5 and implies that the effect of context (i.e., the increase in the probability of choosing $\mathrm{B}$ when option $\mathrm{B}$ moves from a compromise to a dominant position) was stronger for promotion-priming products than for prevention-priming products (the probability of choosing of B was indeed expected to decrease for prevention-priming products).

The analysis was replicated using an index of relative attractiveness of option B (computed in the same manner as in study 1). Additional support for hypothesis 5 was found in the positive cross-level interaction $\left(\gamma_{11}=1.85 ; p<\right.$ $.001)$, which confirms that the effect of context on the relative attractiveness of brand $\mathrm{B}$ depends on the product type. A graphical representation of the effect is shown in figure 1. In sum, results from the multilevel models, combined with those from the analyses of choice patterns converge to the conclusion that prevention-type products are more attractive when positioned as compromise options than when 
FIGURE 1

ATTRACTIVENESS OF COMPROMISE VERSUS DOMINANT BRANDS ACROSS PRODUCT TYPES

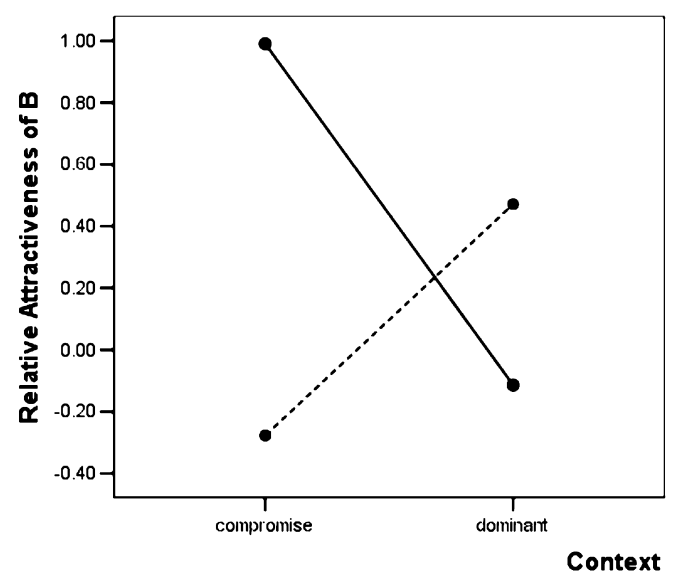

positioned as asymmetrically dominant options, whereas the opposite is true for promotion-type products.

\section{DISCUSSION}

Consumer choice behavior has traditionally been explained in terms of its underlying cognitive processes. Recent research, however, has shown that choice is also influenced by a range of motivational factors. If we consider choice as a series of processes involving information acquisition and different types of comparative operations, then one could argue that motivation may play a role at each of these stages. For example, motivational processes do not only lead to biased information weighting (Chernev 2004b, Lee 2003) but may also affect how alternatives are compared and information is integrated.

In this article, regulatory focus theory (Higgins 1997) was proposed as a parsimonious framework for analyzing the motivational processes underlying context effects in choice. Indeed, unlike other motivational approaches, regulatory focus theory is not founded on consumers' specific goals, needs, and motives, which are virtually infinite. Instead, it is rooted in the strategic inclinations for attaining these goals, needs, and motives, which are organized into two broad categories: promotion focus and prevention focus (Pham and Higgins 2005).

In a series of experiments, we tested the influence of consumers' regulatory orientations on their sensitivity to context effects. We found that when their prevention (as opposed to promotion) system of self-regulation was activated, consumers displayed a greater sensitivity to the compromise effect and a lower sensitivity to the attraction effect. In addition, the effects of promotion and prevention motivations were amplified when consumers were asked to justify their choices. Finally, we found that different products prompted different regulatory concerns and led to different patterns of sensitivity to context effects. Products associated with a prevention concern were more attractive when presented as compromise options, while products associated with a promotion concern were more attractive when presented as dominant options.

We advanced that vigilance versus eagerness in decisionmaking explains the observed effects. Nonetheless, future work is required to reach an unambiguous understanding of the regulatory-focus mechanism that drives these effects. A possible process-level explanation relates to the work of Brockner et al. (2002). Past research (Bazerman 1998) indicates that people have a tendency to overestimate the likelihood of conjunctive events while underestimating the likelihood of disjunctive events. Brockner et al. (2002) recently qualified this effect. The authors reasoned that promotionfocused people's preference for eager strategies and their desire to maximize hits make them more sensitive to the sufficiency notion that only one of several preconditions must be met for an event to occur. Thus, promotion-focused individuals should be less likely to underestimate the occurrence of disjunctive events. However, prevention-focused people's preference for vigilant strategies and their desire to make correct rejections make them more sensitive to the necessity notion that if only one of the preconditions is not met, the conjunctive event will not take place. Therefore, prevention-focused individuals should be less likely to overestimate the occurrence of conjunctive events. It is possible that differences in sensitivity to the compromise effect across prevention and promotion motivations are in fact manifestations of differences in conjunctive (I want $\mathrm{A}$ and $\mathrm{B}$ and $\mathrm{C}$ in a product) versus disjunctive thinking (I want a product that is either $\mathrm{A}$ or $\mathrm{B}$ or $\mathrm{C}$ ). This explanation, however, cannot easily account for differences in sensitivity to the attraction effect. Clearly, more research is needed to shed light on how exactly regulatory focus leads to the observed effects.

More research is also needed that identifies some boundary conditions of the present effects. It is possible, for instance, that sensitivity to context effects is not only a function of regulatory focus but also regulatory focus compatibility (Lee 2003). That is, sensitivity to the compromise and attraction effects might further depend on the type of attribute considered in the trade-off. A preventionfocused consumer, for example, may not compromise on safety and may be highly sensitive to the attraction effect when the dominant brand is dominant on prevention attributes.

The focus of the present article was on how regulatory orientation influences consumers' sensitivity to context effects. But we may also look at this relation from a different angle. Does the presence of a compromise option in a choice set trigger a prevention focus? Alternatively, does the presence of a dominant option in the choice set activate a promotion focus? The answer to these questions will shed further light on the role of motivation in making better and more satisfactory choices. 


\section{APPENDIX A}

\section{CHOICE SETS FOR STUDIES 1 AND 2}

TABLE A1

TOOTHPASTE

\begin{tabular}{|c|c|c|c|c|}
\hline Brand & $\begin{array}{l}\text { Breath-freshening } \\
\text { effectiveness } \\
\text { (rated 1-10) }\end{array}$ & $\begin{array}{l}\text { Tooth-whitening } \\
\text { effectiveness } \\
\text { (rated 1-10) }\end{array}$ & $\begin{array}{l}\text { Cavity-fighting } \\
\text { effectiveness } \\
\text { (rated 1-10) }\end{array}$ & $\begin{array}{c}\text { Price } \\
(\$)\end{array}$ \\
\hline A & 8 & 6 & 8 & 2.99 \\
\hline B & 7 & 7 & 8 & 2.99 \\
\hline C & 6 & 8 & 8 & 2.99 \\
\hline
\end{tabular}

TABLE A2

PRINTER

\begin{tabular}{lcccc}
\hline \hline & & & & Text cost \\
Brand & $\begin{array}{c}\text { Text quality } \\
(\text { rated 1-10) }\end{array}$ & $\begin{array}{c}\text { Text speed } \\
\text { (pages per minute) }^{\mathrm{b}}\end{array}$ & ${\text { page })^{\mathrm{c}}}^{\mathrm{a}}$ & $\begin{array}{c}\text { Price } \\
(\$)\end{array}$ \\
\hline A & 7 & 8 & 2.0 & 200 \\
B & 8 & 8 & 3.5 & 200 \\
C & 9 & 8 & 5.0 & 200 \\
\hline
\end{tabular}

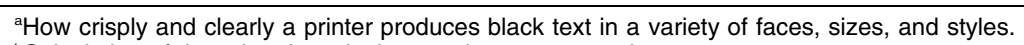

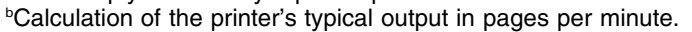

${ }^{\circ}$ Estimated cost of black ink and paper to produce a single text page.

TABLE A3

RESTAURANT

\begin{tabular}{lccccc}
\hline \hline & $\begin{array}{c}\text { Food quality } \\
\text { (rated 1-10) }\end{array}$ & $\begin{array}{c}\text { Atmosphere } \\
\text { (rated 1-10) }\end{array}$ & $\begin{array}{c}\text { Average queuing } \\
\text { time (minutes) }\end{array}$ & $\begin{array}{c}\text { Driving distance } \\
\text { (minutes) }\end{array}$ & $\begin{array}{c}\text { Price per person } \\
(\$)\end{array}$ \\
\hline A & 10 & 6 & 20 & 15 & 40 \\
B & 8 & 8 & 20 & 15 & 40 \\
C & 6 & 10 & 20 & 15 & 40 \\
\hline
\end{tabular}

TABLE A4

ELECTRIC GRILL

\begin{tabular}{|c|c|c|c|c|c|}
\hline Brand & $\begin{array}{l}\text { Cooking quality } \\
(\text { rated } 1-10)^{a}\end{array}$ & $\begin{array}{l}\text { Cooking area } \\
\text { (square inches) }\end{array}$ & 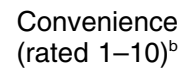 & $\begin{array}{l}\text { Cooking speed } \\
(\text { rated } 1-10)^{c}\end{array}$ & $\begin{array}{l}\text { Price } \\
(\$)\end{array}$ \\
\hline$A$ & 10 & 128 & 8 & 6 & 100 \\
\hline$B$ & 10 & 128 & 6 & 8 & 100 \\
\hline$C$ & 10 & 128 & 5 & 7 & 100 \\
\hline
\end{tabular}


TABLE A5

BIKE HELMET

\begin{tabular}{lccccc}
\hline \hline Brand & $\begin{array}{c}\text { Impact (rated } \\
1-10)^{\mathrm{a}}\end{array}$ & $\begin{array}{c}\text { Retention } \\
(\text { rated 1-10) }\end{array}$ & $\begin{array}{c}\text { Ventilation } \\
(\text { rated 1-10) }\end{array}$ & $\begin{array}{c}\text { Ease of use } \\
(\text { rated 1-10 })^{\mathrm{d}}\end{array}$ \\
\hline A & 8 & 9 & 9 & 6 & $\begin{array}{c}\text { Price } \\
(\$)\end{array}$ \\
B & 8 & 9 & 7 & 8 & 45 \\
C & 8 & 9 & 6 & 8 & 45 \\
\hline
\end{tabular}

aHow well the helmet absorbs energy in impact tests.

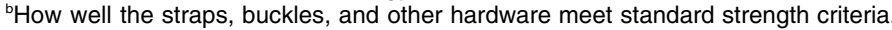

'How well air flows through the helmet.

'How easily the helmet's straps, buckles, and other hardware can be adjusted.

TABLE A6

PORTABLE PHONE

\begin{tabular}{lcccc}
\hline \hline Brand & $\begin{array}{c}\text { Voice quality } \\
(\text { rated 1-10) }\end{array}$ & $\begin{array}{c}\text { Talk time } \\
\text { (hours) }^{\mathrm{a}}\end{array}$ & $\begin{array}{c}\text { Ease of use } \\
\text { (rated 1-10) }^{\mathrm{b}}\end{array}$ & $\begin{array}{c}\text { Price } \\
(\$)\end{array}$ \\
\hline A & 9 & 8 & 8 & 35 \\
B & 7 & 10 & 8 & 35 \\
C & 6 & 9 & 8 & 35 \\
\hline \multicolumn{2}{l}{ aHow long you can converse on the handset when it is fully charged. } \\
bIncludes handset weight and comfort, ease of phone setup and use, and size of controls and buttons.
\end{tabular}

APPENDIX B

CHOICE SETS FOR STUDY 3: COMPROMISE STRUCTURE

TABLE B1

SUNSCREEN

\begin{tabular}{lccc}
\hline \hline Brand & $\begin{array}{c}\text { UVA protection } \\
\text { (rated 1-10) }\end{array}$ & $\begin{array}{c}\text { UVB protection } \\
\text { (rated 1-10) }\end{array}$ & $\begin{array}{c}\text { Price } \\
(\$)\end{array}$ \\
\hline A & 9 & 6 & 7.99 \\
B & 8 & 7 & 7.99 \\
C & 7 & 8 & 7.99 \\
\hline \multicolumn{4}{r}{ NotE.-UVA and UVB are two radiation wavelengths produced by the sun that } \\
may dame the skin.
\end{tabular}

TABLE B2

\begin{tabular}{|c|c|c|c|}
\hline \multicolumn{4}{|c|}{ WINE } \\
\hline Brand & $\begin{array}{c}\text { Body } \\
(\text { rated } 1-10)^{a}\end{array}$ & $\begin{array}{l}\text { Complexity } \\
{\text { (rated } 1-10)^{\mathrm{b}}}\end{array}$ & $\begin{array}{l}\text { Price } \\
(\$)\end{array}$ \\
\hline A & 8 & 6 & 19 \\
\hline B & 7 & 7 & 19 \\
\hline C & 6 & 8 & 19 \\
\hline
\end{tabular}


TABLE B3

MOUTHWASH

\begin{tabular}{lccc}
\hline \hline Brand & $\begin{array}{c}\text { Germ-killing } \\
\text { effectiveness } \\
\text { (rated 1-10) }\end{array}$ & $\begin{array}{c}\text { Decay-preventing } \\
\text { effectiveness } \\
\text { (rated 1-10) }\end{array}$ & $\begin{array}{c}\text { Price } \\
(\$)\end{array}$ \\
\hline A & 9 & 6 & 4.50 \\
B & 7 & 8 & 4.50 \\
C & 6 & 9 & 4.50
\end{tabular}

TABLE B4

FINE RESTAURANT

\begin{tabular}{lcccc}
\hline \hline Restaurant & $\begin{array}{c}\text { Food quality } \\
\text { (rated 1-10) }\end{array}$ & $\begin{array}{c}\text { Atmosphere } \\
\text { (rated 1-10) }\end{array}$ & $\begin{array}{c}\text { Driving distance } \\
\text { (minutes) }\end{array}$ & $\begin{array}{c}\text { Price per } \\
\text { person (\$) }\end{array}$ \\
\hline A & 9 & 6 & 15 & 40 \\
B & 7 & 7 & 15 & 40 \\
C & 6 & 9 & 15 & 40 \\
\hline
\end{tabular}

\section{APPENDIX C}

\section{CHOICE SETS FOR STUDY 3: ASYMMETRIC DOMINANCE STRUCTURE}

TABLE C1

SUNSCREEN

\begin{tabular}{lccc}
\hline \hline Brand & $\begin{array}{c}\text { UVA protection } \\
\text { (rated 1-10) }\end{array}$ & $\begin{array}{c}\text { UVB protection } \\
\text { (rated 1-10) }\end{array}$ & $\begin{array}{c}\text { Price } \\
(\$)\end{array}$ \\
\hline A & 9 & 6 & 7.99 \\
B & 8 & 7 & 7.99 \\
C & 6 & 7 & 7.99 \\
\hline \multicolumn{4}{r}{ NoTE.-UVA and UVB are two radiation wavelengths produced by the sun that } \\
may damage the skin.
\end{tabular}

TABLE C2

\begin{tabular}{lccc}
\multicolumn{4}{c}{ WINE } \\
\hline \hline Brand & $\begin{array}{c}\text { Body } \\
(\text { rated 1-10) }\end{array}$ & $\begin{array}{c}\text { Complexity } \\
(\text { rated 1-10) }\end{array}$ & $\begin{array}{c}\text { Price } \\
(\$)\end{array}$ \\
\hline A & 8 & 6 & 19 \\
B & 7 & 7 & 19 \\
C & 6 & 7 & 19 \\
\hline aThe perception of texture and weight of the wine in the mouth. \\
'DThe perception of multiple layers and nuances of bouquet and flavor.
\end{tabular}


TABLE C3

\begin{tabular}{lccc}
\multicolumn{4}{c}{ MOUTHWASH } \\
\hline \hline Brand & $\begin{array}{c}\text { Germ-killing } \\
\text { effectiveness } \\
\text { (rated 1-10) }\end{array}$ & $\begin{array}{c}\text { Decay-preventing } \\
\text { effectiveness } \\
\text { (rated 1-10) }\end{array}$ & $\begin{array}{c}\text { Price } \\
(\$)\end{array}$ \\
\hline A & 9 & 6 & 4.50 \\
B & 7 & 8 & 4.50 \\
C & 6 & 8 & 4.50 \\
\hline
\end{tabular}

TABLE C4

FINE RESTAURANT

\begin{tabular}{lcccc}
\hline \hline Restaurant & $\begin{array}{c}\text { Food quality } \\
\text { (rated 1-10) }\end{array}$ & $\begin{array}{c}\text { Atmosphere } \\
\text { (rated 1-10) }\end{array}$ & $\begin{array}{c}\text { Driving distance } \\
\text { (minutes) }\end{array}$ & $\begin{array}{c}\text { Price per } \\
\text { person (\$) }\end{array}$ \\
\hline A & 9 & 6 & 15 & 40 \\
B & 7 & 7 & 15 & 40 \\
C & 5 & 7 & 15 & 40 \\
\hline
\end{tabular}

\section{REFERENCES}

Aaker, Jennifer L. and Angela Y. Lee (2001), "'I' Seek Pleasures, 'We' Avoid Pains: The Role of Self-Regulatory Goals in Information Processing and Persuasion," Journal of Consumer Research, 28 (June), 33-49.

$\rightarrow$ Ariely, Dan and Thomas S. Wallsten (1995), "Seeking Subjective Dominance in Multidimensional Space: An Explanation of the Asymmetric Dominance Effect," Organizational Behavior and Human Decision Processes, 63 (September), 223-32.

Bazerman, Max (1998), Judgment in Managerial Decision Making, 4th ed., New York: Wiley.

$\rightarrow$ Briley, Donnel A., Michael W. Morris, and Itamar Simonson (2000), "Reasons as Carriers of Culture: Dynamic versus Dispositional Models of Cultural Influence on Decision Making," Journal of Consumer Research, 27 (September), 157-78.

$\rightarrow$ Brockner, Joel, Srikanth Paruchuri, Lorraine Chen Idson, and E. Tory Higgins (2002), "Regulatory Focus and the Probability Estimates of Conjunctive and Disjunctive Events," Organizational Behavior and Human Decision Processes, 87 (January), 5-24.

$\rightarrow$ Chernev, Alexander (2004a), "Extremeness Aversion and Attribute-Balance Effects in Choice," Journal of Consumer Research, 31 (September), 249-63.

$\rightarrow$ (2004b), "Goal-Attribute Compatibility in Consumer Choice," Journal of Consumer Psychology, 14 (1-2), 141-50.

$\rightarrow$ Crowe, Ellen and E. Tory Higgins (1997), "Regulatory Focus and Strategic Inclinations: Promotion and Prevention in DecisionMaking," Organizational Behavior and Human Decision Processes, 69 (2), 117-32.

$\rightarrow$ Dhar, Ravi and Rashi Glazer (1996), "Similarity in Context: Cognitive Representation and Violation of Preference and Perceptual Invariance in Consumer Choice," Organizational Behavior and Human Decision Processes, 67 (September), 280-93.

$\rightarrow$ Forster, Jens, E. Tory Higgins, and Amy Taylor Bianco (2003), "Speed/Accuracy Decisions in Task Performance: Built-in
Tradeoff or Separate Strategic Concerns?" Organizational Behavior and Human Decision Processes, 90 (1), 148-64.

$\rightarrow$ Higgins, E. Tory (1997), "Beyond Pleasure and Pain," American Psychologist, 52 (12), 1280-1300.

_ (1998), "Promotion and Prevention: Regulatory Focus as a Motivational Principle," in Advances in Experimental Social Psychology, Vol. 30, ed. Mark P. Zanna, San Diego: Academic Press, 1-46.

$\rightarrow$ Higgins, E. Tory, Ronald S. Friedman, Robert E. Harlow, Lorraine Chen Idson, Ozlem N. Ayduk, and Amy Taylor (2001), "Achievement Orientations from Subjective Histories of Success: Promotion Pride versus Prevention Pride," European Journal of Social Psychology, 31 (1), 3-23.

$\rightarrow$ Higgins, E. Tory, Christopher J. R. Roney, Ellen Crowe, and Charles Hymes (1994), "Ideal versus Ought Predilections for Approach and Avoidance: Distinct Self-Regulatory Systems," Journal of Personality and Social Psychology, 66 (February), 276-86.

$\rightarrow$ Huber, Joel, John W. Payne, and Christopher Puto (1982), “Adding Asymmetrically Dominated Alternatives: Violation of Regularity and the Similarity Hypothesis," Journal of Consumer Research, 9 (June), 90-98.

Kivetz, Ran, Oded Netzer, and V. Srinivasan (2004), "Alternative Models for Capturing the Compromise Effect," Journal of Marketing Research, 41 (3), 237-57.

Lee, Angela Y. (2003), “The Influence of Self-Regulatory Goal on Information Processing, Affective Responses, and Counterfactual Thinking," Advances in Consumer Research, Vol. 30, ed. Punam Anand Keller and Dennis W. Rook, Toronto: Association for Consumer Research, 82-84.

Luce, R. Duncan (1959), Individual Choice Behavior: A Theoretical Analysis, New York: Wiley.

$\rightarrow$ (1977), "The Choice Axiom after Twenty Years," Journal of Mathematical Psychology, 15 (2), 215-33.

Mishra, Sanjay, U. N. Umesh, and Donald E. Stem Jr. (1993), "Antecedents of the Attraction Effects," Journal of Marketing Research, 30 (August), 331-49.

Pettibone, Jonathan C. and Douglas H. Wedell (2000), "Examining 
Models of Nondominated Decoy Effects across Judgment and Choice," Organizational Behavior and Human Decision Processes, 81 (March), 300-328.

$\rightarrow$ Pham, Michel Tuan and Tamar Avnet (2004), "Ideals and Oughts and the Reliance on Affect versus Substance in Persuasion," Journal of Consumer Research, 30 (March), 503-18.

Pham, Michel Tuan and E. Tory Higgins (2005), "Promotion and Prevention in Consumer Decision Making: State of the Art and Theoretical Proposition," in Inside Consumption: Frontiers of Research on Consumer Motives, Goals, and Desires, ed. Srinivasan Ratneshwar and David Glen Mick, London: Routledge, 8-43.

Ratneshwar, S., David Glen Mick, and Cynthia Huffman (2000), The Why of Consumption: Contemporary Perspectives on Consumer Motives, Goals, and Desires, New York: Routledge.

$\rightarrow$ Ratneshwar, Srinivasan, Allan D. Shocker, and David W. Stewart (1987), "Toward Understanding the Attraction Effect: The Implications of Product Stimulus Meaningfulness and Familiarity," Journal of Consumer Research, 13 (March), 520-33.

Raudenbush, Steven W., Anthony S. Bryk, Yuk F. Cheong, and Richard Congdon (2000), HLM 5: Hierarchical Linear and
Nonlinear Modeling (computer software), Lincolnwood, IL: Scientific Software International.

(2001), HLM 5: Hierarchical Linear and Nonlinear Modeling, Lincolnwood, IL: Scientific Software International.

$\rightarrow$ Sen, Sankar (1998), "Knowledge, Information Mode, and the Attraction Effect," Journal of Consumer Research, 25 (June), 64-77.

Simonson, Itamar (1989), "Choice Based on Reasons: The Case of Attraction and Compromise Effects," Journal of Consumer Research, 16 (September), 158-74.

Simonson, Itamar and Stephen M. Nowlis (2000), "The Role of Explanations and Need for Uniqueness in Consumer Decision Making: Unconventional Choices Based on Reasons," Journal of Consumer Research, 27 (June), 49-68.

$\rightarrow$ Simonson, Itamar and Amos Tversky (1992), "Choice in Context: Tradeoff Contrast and Extremeness Aversion," Journal of Marketing Research, 29 (3), 281-95.

$\rightarrow$ Zhou, Rongrong and Michel Tuan Pham (2004), "Promotion and Prevention across Mental Accounts: When Financial Products Dictate Consumers' Investment Goals," Journal of Consumer Research, 31 (June), 125-35. 